\title{
STUDI KASUS SISTEM PENCARIAN DATA PENDUDUK MENGGUNAKAN METODE STUDY PRACTICE
}

\author{
Muhamad Dandi $^{1}$, Kinky Fernando ${ }^{2}$, Taufik Hidayat ${ }^{3}$ \\ ${ }^{1,2,3}$ Department of Computer Engineering, Universitas Wiralodra, Indonesia \\ ${ }^{1}$ muhamaddandi768@gmail.com, ${ }^{2}$ kinkifernando@gmail.com, ${ }^{3}$ thidayat.ft@unwir.ac.id
}

\begin{abstract}
ABSTRAK
Sistem kependudukan yang selalu up to date sangat dibutuhkan untuk kegiatan pelayanan masyarakat di bidang administrasi kependudukan pada suatu pemerintahan baik di daerah maupun pusat. Namun kondisi yang terjadi di masyarakat menunjukkan bahwa pelayanan masyarakat tersebut belum maksimal. Sistem kependudukan di Desa Patrol Lor saat ini masih manual sehingga kurang efisien dalam pengelolaan informasinya. Proses pelayanan pencarian data penduduk dari pihak desa masih dilakukan secara manual sehingga bisa dikatakan kurang efisien dalam melayani masyarakat. Pemanfaatan teknologi yang sudah ada dapat dilakukan dengan tujuan dapat menghemat waktu dan tenaga, oleh karena itu dibutuhkan sebuah sistem aplikasi kependudukan desa. Sistem aplikasi kependudukan di Desa Patol Lor ini dirancang untuk memudahkan pencarian NIK dengan menggunakn metode study practice dengan melalukan proses pretest dan posttest untuk mengetahui kebenaran hasil dari pemrosesan data serta melakukan analisa terhadap sistem tersebut. Sehingga dengan adanya sistem aplikasi kepedudukan desa ini dapat meningkatkan kualitas pelayanan bagi petugas desa dan dapat mempermudah petugas desa dalam mencari dan mengedit data kependudukan sehingga mempermudah melayani penduduk atau warga dalam mengontrol data penduduk dan menyediakan laporan kependudukan yang tepat dan akurat. Pada penelitian selanjutnya agar mengkombinasikan dengan metode laian akan system pencarian semakin cepat.
\end{abstract}

Kata Kunci : Desa Patrol Lor, Sistem Kependudukan, NIK, Metode Study Practice

\begin{abstract}
Population system always up to date is really needed community service in population administration at a governmental buildings in the regions and central. One of the indications that emerged in the community shows that the community service has not yet been optimized.Population system in the village patrol lor is still manual so that inefficient in the management of the information. Service process for finding data inhabitant of village stakeholders is still done manually so that it can be said inefficient in serving the public .The utilization of technology that had been prepared in can be done by the excuse that they could saves both time and energy, hence it takes an population the application system of village. The application system of population in the village patol lor is designed using microsoft excel and visual basic aplication. The trial on alikasi made with the study practice and do the pretest and posttest know the results of data processing and analysis of the system. So that created an application up ringkat village population will increase the quality of service to the village and to simplify village officials in finding and edit and population data to serve citizens or residents of the control and administration report precisely and accurately.
\end{abstract}

Keywords: Patrol Lor Village, Population System, NIK, Study Practice Method 


\section{PENDAHULUAN}

Sistem informasi kependudukan merupakan bagian dari sistem informasi administrasi kependudukan negara yang mempunyai jangkauan lebih luas. Sejalan dengan arah penyelenggaraan administrasi kependudukan, maka pendataan penduduk perlu ditata sebaik mungkin agar memberikan manfaat dalam perbaikan pemerintahan [1]. Perkembangan teknologi yang semakin modern dan laju pertumbuhan penduduk Indonesia yang semakin tinggi menuntut adanya sistem teknologi informasi kependudukan yang lebih canggih. Perkembangan teknologi yang semakin modern dan laju pertumbuhan penduduk Indonesia yang semakin tinggi menuntut adanya sistem teknologi informasi kependudukan yang lebih canggih [2], [3]. Sehingga sistem tersebut diharapkan dapat mempermudah dalam pencarian dan pengolahan informasi data kependudukan secara akurat dan efisien. Selain itu, dengan menggunakan pengolahan database maka pengolahan data menjadi terorganisasi dalam satu tempat penyimpanan sehingga memudahkan pihak desa atau keluharan dalam pengoperasiannya dan memperkecil kesalahan yang mungkin terjadi serta memudahkan dalam pembuatan laporan kependudukan [4]. Sistem kependudukan di Desa Patrol Lor saat ini masih manual sehingga kurang efisien dalam pengolahan informasinya. Proses input data dari pihak desa yang masih manual dan pencarian data penduduk yang belum otomatis membuat pelayanan desa kurang efisien [5].

Dengan adanya permasalahan tersebut dan agar dapat menghemat waktu dan tenaga, maka perlu adanya sistem aplikasi kependudukan tingkat desa untuk meningkatkan kualitas pelayanan bagi petugas desa dan dapat mempermudah dalam pencarian dan pengolahan informasi data kependudukan secara akurat dan efisien serta dapat mempermudah petugas desa dalam pengumpulan data penduduk desa dan mempercepat pelayanan [6]. Tujuan aplikasi ini adalah untuk menyajikan informasi kependudukan secara cepat dan akurat. Dengan harapan dapat membantu mengatasi permasalahan dalam pelayanan administrasi kependudukan dan mempermudah dalam pengolahan data kependudukan, serta dengan menggunakan pengolahan database maka pengolahan data menjadi terorganisasi dalam satu tempat penyimpanan. Sedangkan manfaat dari sistem aplikasi ini adalah dapat mempermudah petugas desa dalam mencari dan mengedit data kependudukan sehingga mempermudah melayani penduduk atau warga dalam mengontrol data penduduk dan menyediakan laporan kependudukan yang tepat dan akurat.

Terdapat banyak kasus yang dapat diselesaikan dengan VBA (Visual Basic for Aplication) [7]. Karena dengan VBA ini sistem atau aplikasi dapat dibuat sesuai dengan kebutuhan atau masalah yang ada. Oleh karena itu di Desa sangat membutuhkan sebuah sistem aplikasi administrasi desa dan penggunaan Microsoft Excel VBA [8] dapat mengatasi permasalahan tersebut. Pada Desa Patrol Lor ini dibutuhkan sebuah sistem yang dapat mencari data penduduk dengan cepat, oleh karena itu sistem ini dibuat untuk membantu menyelesaikan permasalahan pada sistem administrasi desa dalam pelayanan kepada masyarakat bidang data kependudukan [9].

\section{METODE PENELITIAN}

\section{A. Metode Study Practice}

Penelitian ini dilaksanakan di Kantor Desa Patrol Lor Kecamatan Patrol Kabupaten Indramayu. Pendekatan yang digunakan pada program ini dengan menggunakan metode studypractice untuk edukasi dan bimbingan teknis mengoperasikan sistem pencarian data penduduk. Metode ini diterapkan untuk menyelesaikan masalah-masalah yang terjadi dalam pengorasian komputer softwere maupun hardwere [10], serta untuk suatu inovasi dari kekurangan sistem administrasi desa. Berikut penerapan metode study practice:

\section{Perancangan Sistem}

Tujuan perancangan sistem adalah untuk mendifinisikan informasi apa yang dibutuhkan oleh sistem yang akan dibangun sehingga mudah untuk dilakukan transformasi kedalam kode aktual dan bisa memiliki database yang efisien dalam ruang penyimpanan, cepat dalam pengaksesan dan mudah dalam manipulasi seperti tambah, ubah, hapus data [11], [12]. 
Perancangan sistem ini dibuat untuk memberikan gambaran serta penjelasan sistem yang dibuat [13]. Dalam merancang suatu sistem data kependudukan maka dianggap perlu dibuat flowchart untuk mengetahui alur dari penggunaan sistem ini sebagai berikut:

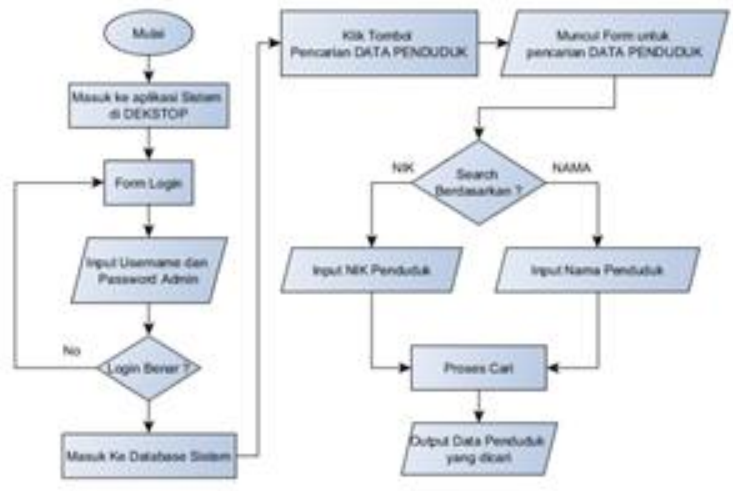

Gambar 1. Flowchart alur sistem

Adapun dataset user dan dataset penduduk yang berisikan atribut, tipe data, dan informasi atribut yang digunakan dalam sistem pencarian data penduduk sebagai berikut :

Tabel 1. Dataset User

\begin{tabular}{|c|c|c|}
\hline Atribut & Tipe Data & $\begin{array}{c}\text { Informasi } \\
\text { Atribut }\end{array}$ \\
\hline Id_user & Number & ID User \\
\hline Username & General & Nama User \\
\hline Password & General & Password User \\
\hline
\end{tabular}

Tabel 2. Dataset Penduduk

\begin{tabular}{|c|c|c|}
\hline Atribut & $\begin{array}{c}\text { Tipe } \\
\text { Data }\end{array}$ & $\begin{array}{c}\text { Informasi } \\
\text { Atribut }\end{array}$ \\
\hline txtreg & Number & No Reg \\
\hline txtnik.Text & Text & NIK \\
\hline txtnama.Text & Text & Nama \\
\hline txtjeniskelamin.Text & Text & JK \\
\hline txttempatlahir.Text & Text & Tempat Lahir \\
\hline txttanggallahir & Date & Tanggal Lahir \\
\hline txtnokk.Text & Text & No.KK \\
\hline txtnamakk.Text & Text & Nama KK \\
\hline txtgoldarah.Text & Text & Gol.Darah \\
\hline txtagama.Text & Text & Agama \\
\hline txtstatus.Text & Text & Status \\
\hline txthubkel.Text & Text & Hub.Keluarga \\
\hline
\end{tabular}

\begin{tabular}{|c|c|c|}
\hline txtpendidikan.Text & Text & Pendidikan \\
\hline txtpekerjaan.Text & Text & Pekerjaan \\
\hline txtibu.Text & Text & Nama Ibu \\
\hline txtayah.Text & Text & Nama Ayah \\
\hline txtket.Text & Text & Keterangan \\
\hline txtdusun.Text & Text & Dusun \\
\hline txtrt.Text & Text & RT \\
\hline txtrw.Text & Text & RW \\
\hline txtdesa.Text & Text & Desa/Kel \\
\hline txtkecamatan.Text & Text & Kecamatan \\
\hline txtkabupaten.Text & Text & Kabupaten \\
\hline txtkodepos.Text & Text & Kode Pos \\
\hline txtprovinsi.Text & Text & Provinsi \\
\hline
\end{tabular}

2. Analisis Sistem

Analisis sistem dilakukan dengan pretest dan posttest sebagai bentuk evaluasi pembelajaran yang digunakan untuk mengukur kompetensi awal dan kompetensi akhir. Kompetensi awal merupakan tingkat pemahaman perserta didik sebelum menerima pembelajaran, sedangkan komptensi akhir merupakan tingkat penguasaan materi setelah menerima pembelajaran [6], [14].

Pretest ini mengacu pada kemampuan subjek diawal. Dengan melakukan pretest akan memperoleh gambaran mengenai pengetahuan dan kemampuan subjek sebelum melakukan bimbingan teknis kepada subjek [15], [6]. Post test dilakukan setelah melakukan bimbingan teknis kepada subjek. Post test ini merupakan bentuk evaluasi akhir dari sebuah pembelajaran yang bertujuan untuk mengetahui keberhasilan proses bimbingan teknis dan mengukur pengusaan kompetensi subjek [5], [16]. Untuk menguji sistem ini, dikalkukan pretest dan post test kepada beberapa subjek yang akan menggunakan sistem pencarian data penduduk otomatis berbabasis VBA ini [8], [17]. Karena dari hasil pretest dan post test dapat diketahui hasil keberhasilan dari sistem ini. Berikut adalah cara perhitungan hasil post test dan pre test : 
Tabel 3. Aturan Perhitungan Hasil Data

\begin{tabular}{|c|c|c|c|c|}
\hline \multicolumn{5}{|c|}{ Sistem Pencarian data penduduk otomatis } \\
\hline \multirow{2}{*}{ Sample } & \multicolumn{2}{|c|}{ Pretest } & \multicolumn{2}{|c|}{ Posttest } \\
\hline & $\mathrm{x}$ & $\mathrm{x}^{2}$ & $\mathrm{y}$ & $y^{2}$ \\
\hline 1 & $\mathrm{x} 1$ & $x^{2} 1$ & $\mathrm{y} 1$ & $\mathrm{y}^{2} 1$ \\
\hline 2 & $\mathrm{x} 2$ & $x^{2} 2$ & $\mathrm{y} 2$ & $y^{2} 2$ \\
\hline 3 & $\mathrm{x} 3$ & $x^{2} 3$ & y3 & $y^{2} 3$ \\
\hline 4 & $\mathrm{x} 4$ & $x^{2} 4$ & $\mathrm{y} 4$ & $y^{2} 4$ \\
\hline 5 & $\mathrm{x} 5$ & $x^{25}$ & $\mathrm{y} 5$ & $y^{2} 5$ \\
\hline total & total 1 & total 2 & total 3 & total 4 \\
\hline$X$ & \multicolumn{2}{|l|}{$\mathrm{X} 1$} & \multicolumn{2}{|l|}{$\mathrm{X} 2$} \\
\hline MAX & \multicolumn{2}{|c|}{ MAX $x$} & \multicolumn{2}{|c|}{ MAX y } \\
\hline MIN & \multicolumn{2}{|c|}{ MIN x } & \multicolumn{2}{|l|}{ MIN y } \\
\hline
\end{tabular}

Rumus Perhitungan :

Total $1=[=\operatorname{SUM}(\mathrm{x} 1: \mathrm{x} 5)]$

Total $2=\left[=\operatorname{SUM}\left(x^{2} 1: x^{2} 5\right)\right]$

Total $3=[=\operatorname{SUM}(\mathrm{y} 1: \mathrm{y} 5)]$

Total $4=\left[=\operatorname{SUM}\left(\mathrm{y}^{2} 1: \mathrm{y}^{2} 5\right)\right]$

$\mathrm{X} 1=[=$ Average $(\mathrm{x} 1: \mathrm{x} 5)]$ atau

$\left\{\frac{x 1+x 2+x 3+x 4+x 5}{\text { banyaknya } x}\right\}$

$\mathrm{X} 2=[=$ Average $(\mathrm{y} 1: \mathrm{y} 5)]$ atau $\left\{\frac{y 1+y 2+y 3+y 4+y 5}{\text { banyaknya } y}\right\}$

$\operatorname{MAX} \mathrm{x}=[=\mathrm{MAX}(\mathrm{x} 1: \mathrm{x} 5)]$

$\operatorname{MIN} \mathrm{x}=[=\operatorname{MIN}(\mathrm{y} 1: \mathrm{y} 5)]$

Hasil yang diperoleh dapat diketahui apakah sistem ini berhasil atau tidak. Hasil yang dianalisa adalah perubahan dari hasil pretest ke hasil posttest.

\section{HASIL DAN PEMBAHASAN}

\section{A. Implementasi Sistem}

Sistem Pencarian Data Penduduk ini tentunya dapat diimplementasikan oleh pegawai desa bidang kependudukan. Berikut adalah gambaran dari implementasi Sistem Pencarian Data Penduduk Otomatis berbasis VBA (Visual Basic Aplication) :

\section{Form Login}

Pada form login ini admin dapat menginputkan akun admin untuk masuk ke dalam sistem. Jadi tidak sembarang orang dapat masuk ke dalam sistem ini. Berikut adalah tampilan login sistem data penduduk Desa Patrol Lor :

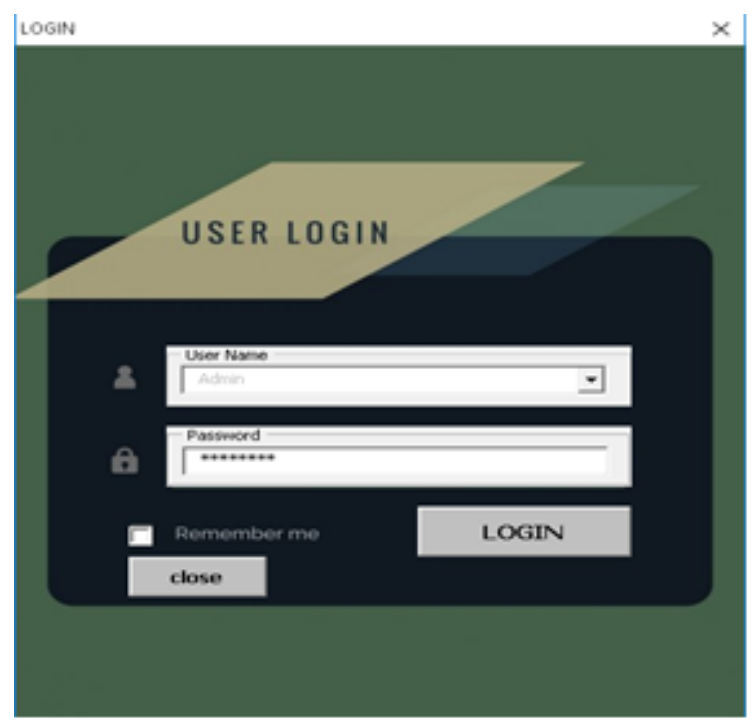

Gambar 2. Halaman Login Sistem

Selanjutnya apabila benar memasukan akun yang sesuai dengan yang dibuat pada database user maka dapat masuk ke sistem dan mendapat notice seperti pada gambar 3 berikut :

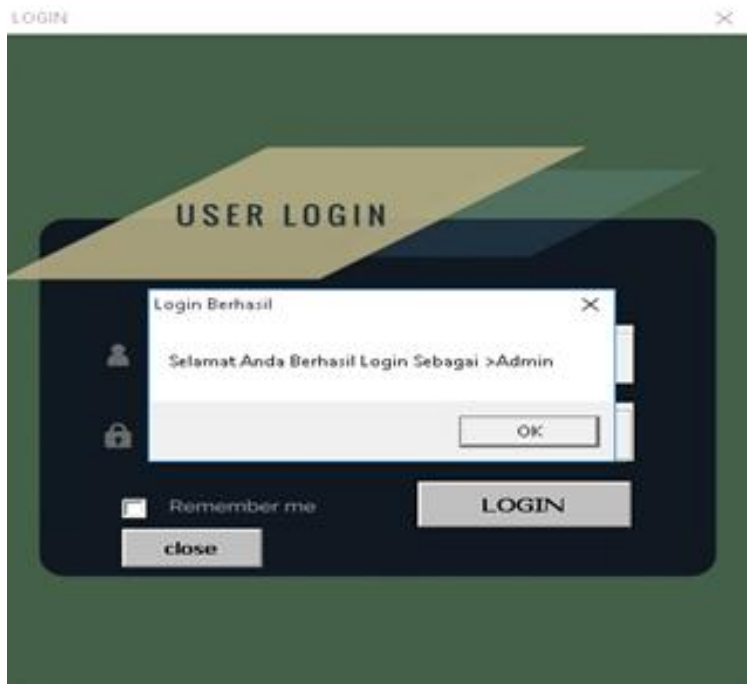

Gambar 3. Notice Login Berhasil

Dan apabila user name dan pasword salah maka diharus kan untuk menghubungi admin untuk mendaftar akun ataupun meminta password baru apabila lupa dengan yang lama. Berikut adalah tampilan notice apabila akun yang dimasukan salah : 


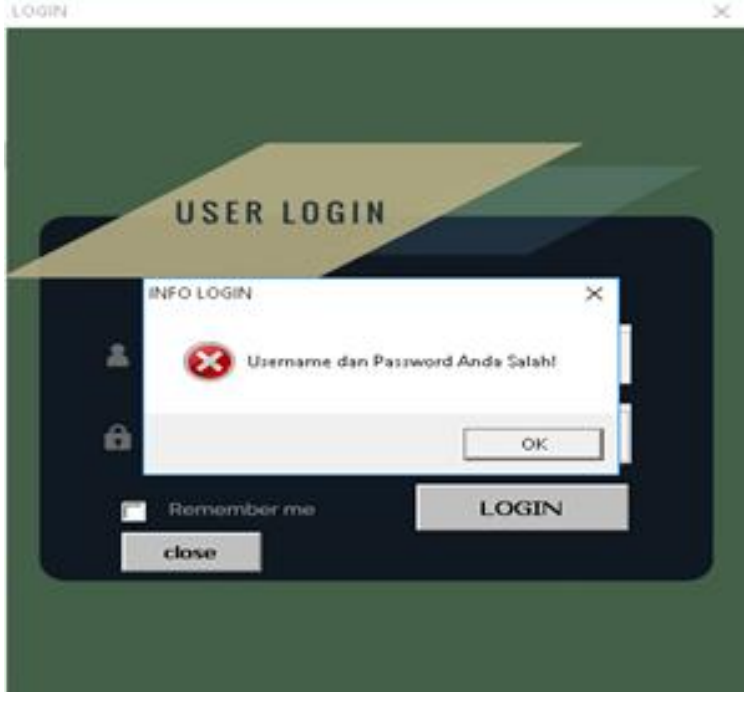

Gambar 4. Notice Login Gagal

\section{Tampilan Database di Microsoft Excel}

Pada sistem ini data penduduk dibagi menjadi 7 worksheet per RW setiap worksheet. Data penduduk Desa Patrol Lor di inputkan melalui database ini sesuai dengan kolom yang sudah dibagi sesuai dengan identitas dari penduduk. Berikut adalah tampilan Data base dari Sistem Pencarian Otomatis Data Penduduk Desa Patrol Lor.

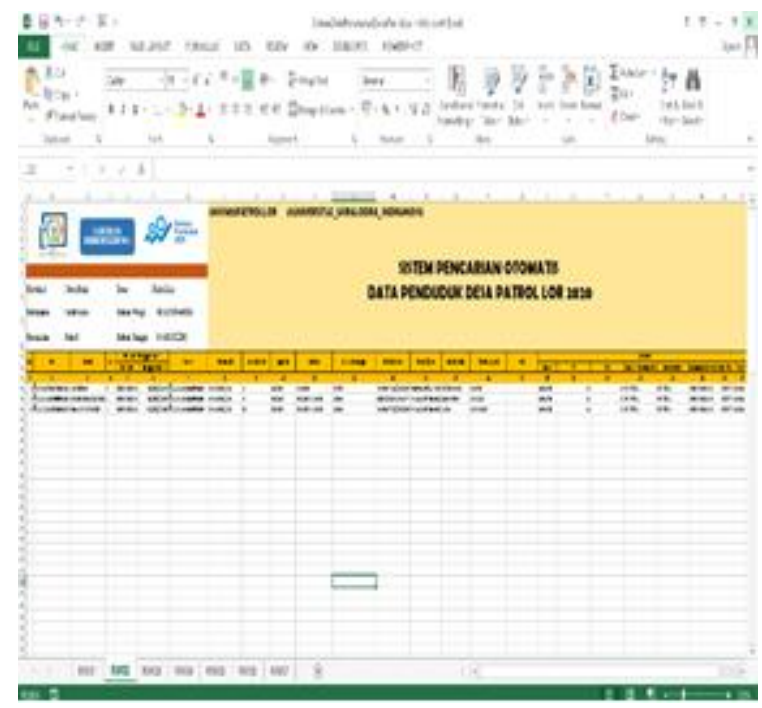

Gambar 5. Tampilan Database Sistem

3. Tampilan Form Pencarian Data Penduduk Otomatis

Form pencarian data penduduk otomatis ini di buat dengan Microsoft VBA (Visual Basic for Aplication) yang didesain untuk bekerja diatas aplikasi lain oleh karena itu pada sistem ini dinamakan VBA Excel karena VBA ini bekerja untuk membantu Excel dalam menyelesaikan pembuatan sistem pencarian data penduduk otomatis ini. Berikut adalah tampilan dari form pencarian data penduduk otomatis yang digunakan untuk mencari data penduduk :

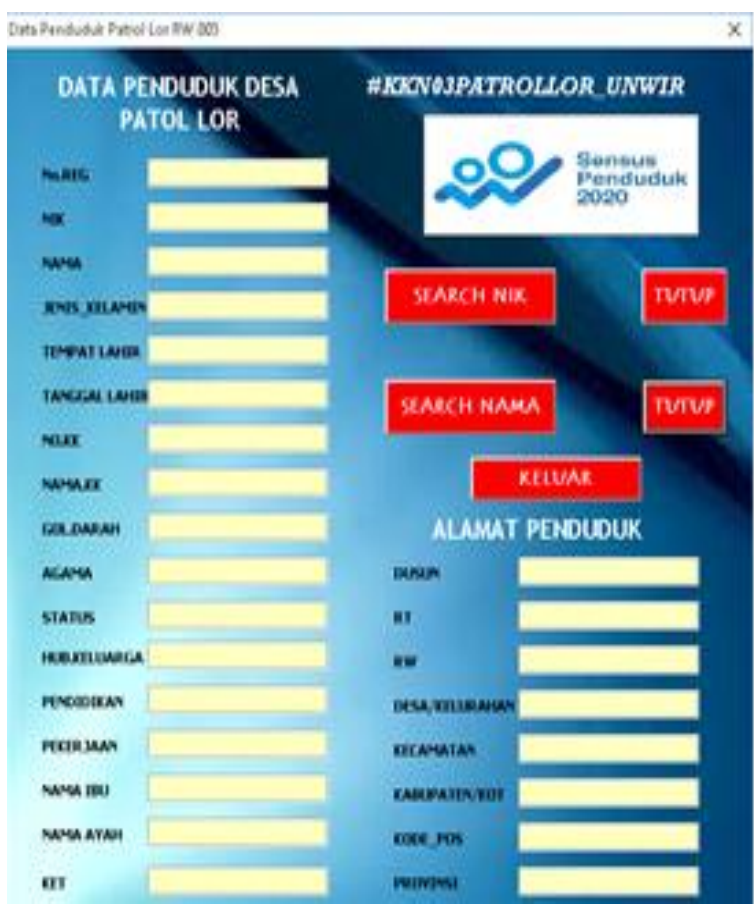

Gambar 6. Form Pencarian Data Penduduk Otomatis

Gambar 6 merupakan form untuk mencari data penduduk otomatis. Pada form tersebut terdapat dua cara untuk mencari data penduduk secara otomatis yakni mencari dengan NIK dan mencari dengan NAMA yang kemudian akan muncul data penduduk sesuai dengan yang ada pada database data penduduk.

\section{B. Uji Data Pretest dan Posttest}

Untuk mendukung metode Study Practice maka dilakukan uji data dengan pretest dan posttest. Pengujian data ini dilakukan dengan bimbingan teknis kepada beberapa subjek atau perangkat desa yang akan menggunakan sistem ini di Kantor Desa Patrol Lor. Data yang diperoleh dari 5 sample dapat dianalisa dari tabel hasil berikut: 
Tabel 5. Hasil Data Pretest dan Postt Sistem Pencarian data penduduk otomatis

\begin{tabular}{|c|c|c|c|c|}
\hline \multirow{2}{*}{ Sample } & \multicolumn{2}{|c|}{ Pretest } & \multicolumn{2}{c|}{ Posttest } \\
\cline { 2 - 5 } & $\mathrm{X}$ & $\mathrm{X}^{2}$ & $\mathrm{y}$ & $\mathrm{Y}^{2}$ \\
\hline 1 & 50 & 2500 & 90 & 8100 \\
\hline 2 & 40 & 1600 & 90 & 8100 \\
\hline 3 & 30 & 900 & 70 & 4900 \\
\hline 4 & 50 & 2500 & 80 & 6400 \\
\hline 5 & 40 & 1600 & 90 & 8100 \\
\hline Jumlah & 210 & 4100 & 250 & 35600 \\
\hline X & \multicolumn{2}{|c|}{42} & \multicolumn{2}{c|}{83,33} \\
\hline MAX & \multicolumn{2}{|c|}{50} & \multicolumn{2}{c|}{90} \\
\hline MIN & \multicolumn{2}{|c|}{30} & \multicolumn{2}{c|}{70} \\
\hline
\end{tabular}

Hasil data pretest dan posttest dapat dibuat grafik seperti gambar 7 dibawah ini :

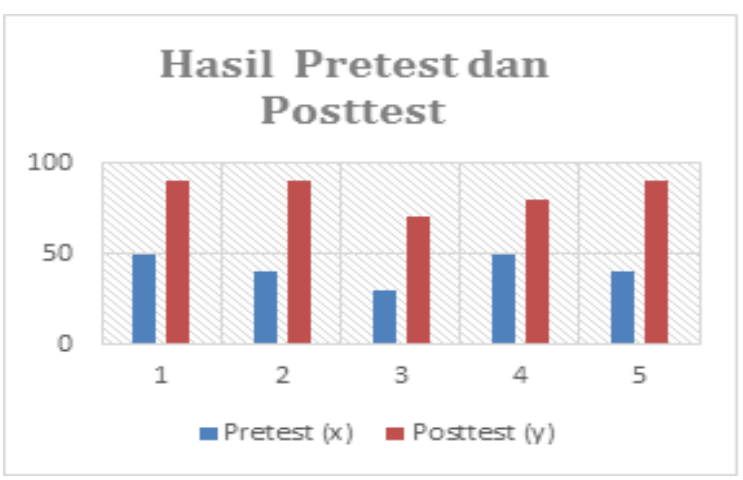

Gambar 7. Grafik Hasil Pretest dan Posttest

Dari hasil pretest dan posttest dapat diketahui bahwa semua sample mendapatkan kenaikan nilai. Hal ini menjadikan penelitian dari sistem ini berhasil dan subjek dapat menggunakan sistem ini dengan semestinya dalam mengelolah data penduduk di Desa Patrol Lor.

\section{KESIMPULAN}

Dari hasil pengujian sistem pencarian data penduduk otomatis berbasis Microsoft Excel VBA sangatlah membantu subjek atau perangkat desa dalam pengolahan data penduduk di Desa Patrol Lor. Berdasarkan adanya kenaikan dari hasil pretest ke hasil posttest menunjukan bahwa pengguna (User) dalam mengoperasikan dan memahami sistem pencarian data penduduk berbasis VBA sudah berhasil dengan semestinya, hal ini dikarenakan dengan adanya bimbingan teknis menggunakan metode Study Practice sehingga sistem ini dapat membantu perangkat desa atau user dalam mengolah data kependudukan dan melayani penduduk dengan cepat dan efisien sehingga dapat dikatakan sistem ini efektif untuk digunakan.

\section{UCAPAN TERIMA KASIH}

Penulis ingin mengucapan terima kasih kepada Perangakat Desa Patrol Lor yang mempercayai kami untuk mengatasi permasalahan mengolah data penduduk sehingga dapat dibuatnya sistem pencarian data penduduk otomatis, dan ucapan terimakasih juga untuk Department of Computer Engineering, Universitas Wiralodra yang selalu mendukung riset kami serta semua kalangan yang terlibat dalam penelitian ini.

\section{DAFTAR PUSTAKA}

[1] T. Ravichandran, C. Lertwongsatien, and C. Ravichandran, T.Lertwongsatien, Chalermsak Lertwongsatien, "Effect of information systems resources and capabilities on firm performance: A resource-based perspective," Journal of Management Information Systems, vol. 21, no. 4, pp. 237-276, Apr. 2005, doi: 10.1080/07421222.2005.11045820.

[2] F. R. Hizkia, N. B. Kurniawan, and Suhardi, "Hybrid IT value model validation for banking sector using partial adjustment valuation," in 2017 International Conference on Information Technology Systems and Innovation (ICITSI), Oct. 2017, vol. 2018-Janua, pp. 54-60, doi: 10.1109/ICITSI.2017.8267918.

[3] L. M. Hitt and E. Brynjolfsson, "Productivity, business profitability, and consumer surplus: Three different measures of information technology value," MIS Quarterly: Management Information Systems, vol. 20, no. 2, pp. 121-142, 1996, doi: 10.2307/249475.

[4] S. Rizq, M. D. Djamaludin, and Y. Nurhadryani, "Analysis of Service Quality Satisfaction of e-KTP Service at Public Administration and Civil Registration office of Bogor District," Journal of Consumer Sciences, vol. 3, no. 2, p. 55, Aug. 2018, doi: 10.29244/jcs.3.2.55-65. 
[5] A. Halik, "The Implementation of Administrative Registration on Population Migration (Case of Surabaya City, East Java Province)," Jurnal Bina Praja, vol. 8, no. 2, pp. 243-251, Nov. 2016, doi: 10.21787/jbp.08.2016.243251.

[6] Z. Peiping and D. Zucheng, "The Design and Implementation of the Examination System Based on the Word - VBA," no. Icmic, pp. 5-9, 2015.

[7] Y. Tan and S. Takakuwa, "A practical simulation approach for an effective truck dispatching system of open pit mines using VBA," Proceedings - Winter Simulation Conference, vol. 0, no. 2009, pp. 2394-2405, 2016, doi: 10.1109/WSC.2016.7822279.

[8] K. Gaik, S. Long, T. Han, and R. Abdulkahar, "The Fourth Order Runge-Kutta Spreadsheet Calculator Using VBA Programing For Ordinary Differential Equations," Procedia - Social and Behavioral Sciences, vol. 204, no. November 2014, pp. 231-239, 2015, doi: 10.1016/j.sbspro.2015.08.145.

[9] M. E. Aminanto, "Development of Protection Profile and Security Target for Indonesia Electronic ID Card's ( KTPel ) Card Reader Based on Common Criteria V3 . 1: 2012 / SNI ISO / IEC 15408 : 2014," pp. 1-6, 2014.

[10] A. D. Method, "SPECIAL PROTECTION SYSTEM WITH MACRO VBA-BASED DESCENDING METHOD AT PT PLN ( PERSERO ) SOUTH AND CENTRAL," pp. 51-54, 2019.

[11] Y. Dai, "Design and implementation of tourism education management system based on web," Proceedings - 2016 International Conference on Intelligent Transportation, Big Data and Smart
City, ICITBS 2016, pp. 428-431, 2017, doi: 10.1109/ICITBS.2016.112.

[12] S.-H. Moon and Y.-H. Kim, "An improved forecast of precipitation type using correlation-based feature selection and multinomial logistic regression," Atmospheric Research, vol. 240, p. 104928, Aug. 2020, doi: 10.1016/j.atmosres.2020.104928.

[13] M. Carcary, E. Doherty, and C. Thornley, "Business innovation and differentiation: Maturing the IT capability," IT Professional, vol. 17, no. 2, pp. 46-53, 2015, doi: 10.1109/MITP.2015.18.

[14] C. Florea, D. David, and A. Pop, "An approach to the didactic activity involving the use of new information and communication technology," Procedia Social and Behavioral Sciences, vol. 2, no. 2, pp. 1699-1702, 2010, doi: 10.1016/j.sbspro.2010.03.968.

[15] S. Kim, S. Hong, J. Oh, and H. Lee, "Obfuscated VBA Macro Detection Using Machine Learning," in 2018 48th Annual IEEE/IFIP International Conference on Dependable Systems and Networks (DSN), Jun. 2018, pp. 490-501, doi: 10.1109/DSN.2018.00057.

[16] Y. Bin, Z. Lei, J. Chun, and F. Shu-hai, "The Design and Development of Incentive Teaching System based on VBA," no. 71171110, pp. 951-954, 2015, doi: 10.1109/ICICTA.2015.241.

[17] A. Sabani, M. H. Farah, and D. R. Sari Dewi, "Indonesia in the Spotlight: Combating Corruption through ICT enabled Governance," Procedia Computer Science, vol. 161, pp. 324332, 2019, doi: 10.1016/j.procs.2019.11.130. 